\title{
Implications of extrapolative factors and their role in the development of breast cancer in females susceptible to Autoimmune Thyroid Disorders (AITDs).
}

\author{
Arif Malik $^{1 *}$, Muhammad Abdul Basit Ashraf ${ }^{1}$, Mahwish Arooj², Sulayman Waquar1, Ayesha Zahid", \\ Rabia Rasool ${ }^{1}$ \\ ${ }^{1}$ Institute of Molecular Biology and Biotechnology (IMBB), the University of Lahore, Lahore, Pakistan \\ ${ }^{2}$ University College of Medicine and Dentistry (UCMD), the University of Lahore, Pakistan
}

\begin{abstract}
Background: Apart from different cancer types in females, breast cancer falls among frequent cancers all over the world. The data from the current studies shows that females with advanced stages of breast cancer also prone to Autoimmune Thyroid Disorders (AITDs).

Methodology: Hundred breast cancer patients (Stage-III) with palpable thyroid nodule in the age group of 30-75 y were eligible for inclusion in the study. Hundred age and sex-matched clinically apparently healthy individuals were included as controls. FT3, FT4, TSH, TPOAb, TgAb, TSHr Ab, prolactin and estradiol were estimated by using ELISA kit method. Serum Protein-Bound Iodine (PBI) and selenium were estimated by using a flow injection hydride generation Atomic Absorption Spectrometric (AAS) method.

Results: The mean age and weight for diseased group were $58.36 \pm 11.78 \mathrm{y}$ and $74.96 \pm 12.66 \mathrm{~kg}$. The decreased levels $(3.73 \pm 0.189 \mathrm{pmol} / \mathrm{L})$ of $\mathrm{T} 3$ were observed in newly diagnosed breast cancer patients as compared to controls $(4.72 \pm 0.24 \mathrm{pmol} / \mathrm{L})$. Higher levels of $\mathrm{T} 4(17.86 \pm 4.98 \mathrm{pmol} / \mathrm{L})$ were recorded in patients as compared to controls $(10.11 \pm 1.64 \mathrm{pmol} / \mathrm{L})$. The serum TSH levels in the breast cancer patients were raised $(3.54 \pm 0.26 \mathrm{mIU} / \mathrm{L})$ in contrary to control group $(1.9 \pm 0.134 \mathrm{mIU} / \mathrm{L})$. Significantly higher levels of Thyroglobulin Antibodies (TgAb), Thyro-Peroxidase Antibodies (TPOAb) and Thyrotropin Stimulating Hormone receptor Antibodies (TSHrAb) were recorded in breast cancer patients $(62.07 \pm 6.94 \mathrm{pmol} / \mathrm{L}, 24.1 \pm 6.81$ and $3.1 \pm 0.43 \mathrm{IU} / \mathrm{L} \mathrm{pmol} / \mathrm{L})$ as compared to controls respectively. The levels of iodine and selenium in patients were reduced $(32.03 \pm 4.76 \mathrm{ng} / \mathrm{ml}$ and $51.03 \pm$ $2.13 \mathrm{mlU} / \mathrm{L})$ as compared to the controls. Highly significant higher serum levels of prolactin $(35.09 \pm$ 4.76) were observed in diseases group as compared to controls $(7.14 \pm 1.57 \mathrm{pg} / \mathrm{ml})$. Serum estrogen levels in patients were $10.47 \pm 1.67 \mathrm{pg} / \mathrm{ml}$, while in healthy individuals they were $6.55 \pm 0.88 \mathrm{pg} / \mathrm{ml}$, which shows statistically highly significant profile between the two groups.

Conclusion: The present study show an association in between breast cancer and thyroid disorders, as thyroid hormone profile regulates breast cancer initiation. Therefore, these biomarkers can be used in prognosis i.e., in management and progression of breast cancer.
\end{abstract}

Keywords: Serum protein-bound iodine (PBI), Thyroglobulin antibodies (Tg-Ab), Thyro-peroxidase antibodies (TPOAb), Thyrotropin stimulating hormone receptor antibodies (TSHr-Ab).

Accepted on January 24, 2018

\section{Introduction}

Cancer has been remained a worldwide hazard to human health as it is the most primary source of death. The World Health Organization (WHO) defines cancer as the rapid formation of abnormal cells which grow beyond their normal limits so that they can metastasize to the organs in close proximity and far away as well. Ratio of cases are believed to increase by the next few decades surveys from year 2015, predicted new cases of cancer world over are 14.1 million and deaths caused by cancer are 8.2 million as compared with 12.7 million and 7.6 million during 2008, respectively [1]. Cancer is the second most leading cause of death after heart disease and about $25 \%$ deaths are caused by cancer [1]. For example, in view of a projection the newly diagnosed cases of cancer in the US alone are likely to be 1.658 million during 2015 and the estimated cancer deaths are 0.589 million expecting about 1,620 people per day to die of cancer. Apart from skin cancers, most frequent cancer in women is the breast cancer. After lung cancer, breast cancer is the second most common cause of 
death in women. In 2015, about 40,290 breast cancer deaths are expected in women. Painless breast lump is the most common symptom of breast cancer. Less likely features of breast cancer are swelling, tenderness, irritation of skin, redness, scaliness and nipple abnormalities including ulceration, retraction, or spontaneous discharge. The modifiable risk factors for breast cancer are iodine deficiency, weight gain, use of hormonal therapy having estrogen and progestin in combination, physical inactivity, smoking, alcohol and stress [2]. Family history of breast cancer, increased breast tissue mass, high bone mineral density, type 2 diabetes, benign breast diseases, high-dose radiation, age at menarche, menopause, recent use of oral contraceptives, age at first pregnancy, and having no children are the non-modifiable risk factors related to breast cancer [3]. Breast cancer is a hormone dependent malignancy [4]. About 100 years ago, Beatson was the first one to suggest the role of thyroid extracts in treating patients with breast cancer [5]. Since then, many reports have proposed the relationship between thyroid disorders and breast cancer but this has not been established in other reports [6,7]. The most commonly observed finding was hypothyroidism in breast cancer patients [8]. Contrary to it, hyperthyroidism may have a protective role against cancer production because metabolism of estrogen and carcinogens is affected by Thyroid Hormones (TH) [9]. Attention towards an association between thyroid and breast is not astonishing as in many investigations, it was found that thyroid diseases and breast cancer are more common in women, but such a link had not been verified by other studies [10,11]. Thyroid neoplasms are three times more common in women as compared to those in men [12]. It has been suggested that hypothyroidism will lead to hyperprolactinemia resulting in breast cancer but on the hand, hyperthyroidism has a direct effect on growth of breast lobules also resulting in cancer [13]. As Thyroid hormone Receptor (TR) and Estrogen Receptors (ER) not only belong to the nuclear receptor superfamily but also the half of nucleotide base sequence of thyroid hormone response element is similar to the estrogen receptor response element half site. It has been revealed that TR binds to ER response element in addition to its respective response element and vice versa in case of ER [14]. Molecular iodine and selenium both have a protective role against breast cancer and their deficiency in diet leads to tumorigenesis. More reliable and prognostic markers for breast cancer are thyroid antibodies and their increase is correlated with breast cancer metastasis.

\section{Aims and Objectives}

The aims and objectives of the present study were to assess the implications of extrapolative factors and their role in the development of breast cancer in females susceptible to Autoimmune Thyroid Disorders (AITDs).

\section{Materials and Methods}

The current study was conducted to evaluate the role of circulating physiological and biochemical variables in newly diagnosed breast cancer patients. All the selected patients were screened at University teaching hospital, the University of Lahore-Pakistan. Hundred breast cancer patients in the age group of 30-75 y were eligible for inclusion in the study. Informed consent was obtained from each patient before being included in this study. Hundred age and sex-matched clinically apparently healthy individuals were selected upon their OPD visit and were included as controls. The experimental protocols were approved by the Research Ethical Committee of The Institute of molecular biology and biotechnology, the University of Lahore. The breast cancer patients (Stage-III) with palpable thyroid nodule were included in the present study. Five $\mathrm{ml}$ of venous blood sample were taken from the anti-cubital vein of each participant. The sample bottles were centrifuged within one hour of collection, after which the serum were separated and stored at $-70^{\circ} \mathrm{C}$ until assayed. Duration of the study remained two years. The patients with the history of exposure to radiotherapy and chemotherapy, surgical excision, hormonal replacement therapy, previously diagnosed thyroid disease, abnormal renal function tests, abnormal hepatic function, use of blocking agents e.g. aspirin, heparin, steroid etc., use of iodine contrasts for at least six month period before and during the study were excluded.

\section{Study design}

The current study design was case-control study.

\section{Demographic data}

Patients with breast cancer were divided in three classes depending upon the invasion/spread of the tumor. Cancer stage is explained as local stage which determines the cancer remains to stage I and to some cases stage II breast cancer in TNM staging system, regional stage that defines the tumor spread to surrounding tissue or nearby lymph nodes the stage corresponds to the stage II and III cancer depending on the size of tumor and distant stage that refers to the metastasis corresponds to stage IIIc and IV.

\section{Estimation of physiological and biochemical variables}

The Free Triiodothyronine (FT3), Thyroxine (T4), Thyroid Stimulating Hormone (TSH), TSH receptor Autoantibody (TSHrAb), Thyroid Peroxidase Antibody (TPOAb) and Thyroglobulin Antibody (TGAb) were estimated by the method of Utiger et al. respectively by using ELISA kit (GenWay Biotech) [15-18]. Prolactin was estimated by prolactin (human) ELISA (Cayman Chemicals) kit method as described by KumKum et al., [19]. Serum Protein-Bound Iodine (PBI) was estimated by the method of Farrell and Richmond [20]. Estradiol was estimated by estradiol (human) ELISA (Cayman Chemicals) kit method as described by Ericson [21]. Blood serum selenium was estimated by the method as described by Combs et al. using a flow injection hydride generation atomic absorption spectrometric (AAS) method [22,23]. 
Implications of extrapolative factors and their role in the development of breast cancer in females susceptible to Autoimmune Thyroid Disorders (AITDs)

\section{Results}

The data presented in Figures 1 and 2 shows clear cut picture of different variables estimated in newly diagnosed breast cancer patients. The mean age and weight for diseased group were $58.36 \pm 11.78 \mathrm{y}$ and $74.96 \pm 12.66 \mathrm{~kg}$ respectively. The levels of $\mathrm{T} 3$ were differed significantly $(\mathrm{p}=0.016)$ between controls and diseased group. The decreased levels $(3.73 \pm$ $0.189 \mathrm{pmol} / \mathrm{L}$ ) of T3 were observed in newly diagnosed breast cancer patients as compared to controls $(4.72 \pm 0.24 \mathrm{pmol} / \mathrm{L})$.

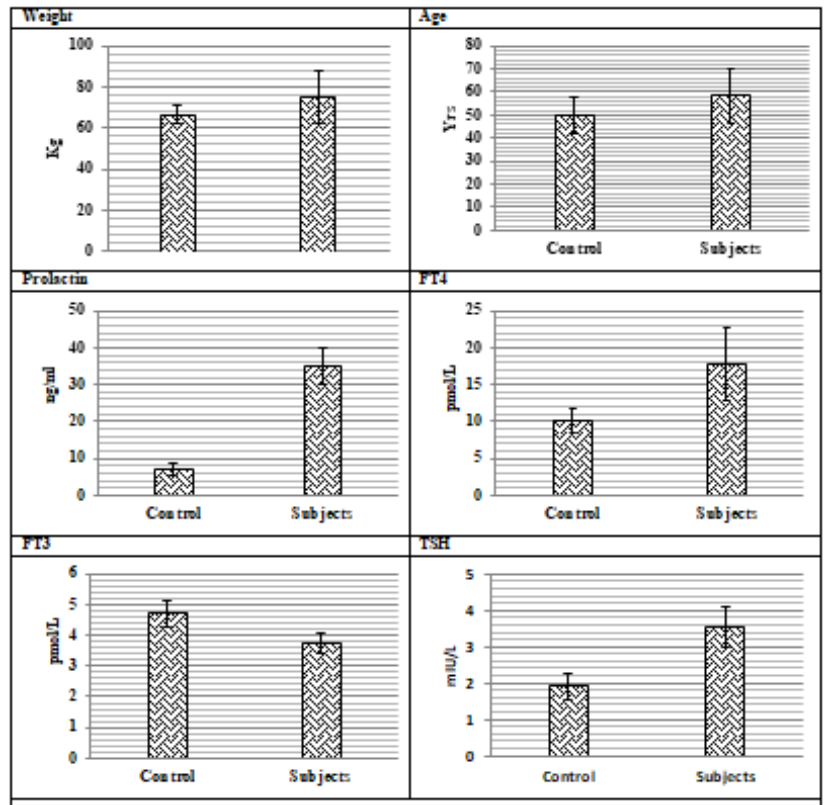

Figure 1. Extrapolative factors of medical importance in newly diagnosed breast cancer patients.

Highly significant $(\mathrm{p}=0.033)$ higher levels of $\mathrm{T} 4(17.86 \pm 4.98$ $\mathrm{pmol} / \mathrm{L}$ ) were recorded in patients as compared to controls $(10.11 \pm 1.64 \mathrm{pmol} / \mathrm{L})$. The serum TSH significant $(\mathrm{p}=0114)$ levels in the breast cancer patients were raised $(3.54 \pm 0.26$ $\mathrm{mIU} / \mathrm{L})$ in contrary to control group $(1.9 \pm 0.134 \mathrm{mIU} / \mathrm{L})$.
Significantly higher levels of Thyroglobulin Antibodies (TgAb), Thyro-Peroxidase Antibodies (TPOAb) and Thyrotropin Stimulating Hormone receptor Antibodies (TSHrAb) were recorded in breast cancer patients $(62.07 \pm$ $6.94 \mathrm{pmol} / \mathrm{L}, 24.1 \pm 6.81 \mathrm{IU} / \mathrm{L}$ and $3.1 \pm 0.43 \mathrm{IU} / \mathrm{L})$ as compared to controls respectively.

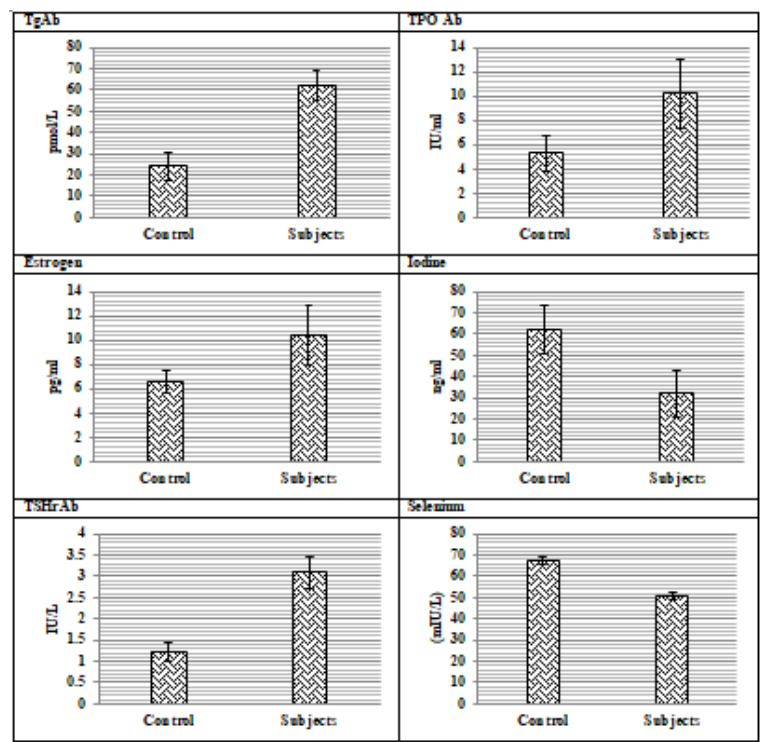

Figure 2. Extrapolative factors of medical importance in newly diagnosed breast cancer patients.

The levels of iodine in patients were reduced $(32.03 \pm 4.76$ $\mathrm{ng} / \mathrm{ml})$ as compared to the control group $(61.88 \pm 5.14 \mathrm{ng} / \mathrm{ml})$. The selenium levels in subjects and controls were $51.03 \pm 2.13$ $\mathrm{mIU} / \mathrm{L}$ and $67.33 \pm 1.79 \mathrm{mIU} / \mathrm{L}$ respectively. Highly significantly higher serum levels of prolactin $(35.09 \pm 4.76$ $\mathrm{pg} / \mathrm{ml}$ ) were observed in diseases group as compared to controls $(7.14 \pm 1.57 \mathrm{pg} / \mathrm{ml})$. Serum estradiol levels in patients were $10.47 \pm 1.67 \mathrm{pg} / \mathrm{ml}$, while in healthy individuals they were $6.55 \pm 0.88 \mathrm{pg} / \mathrm{ml}$ which shows statistically highly significant profile between the two groups (Table 1).

Table 1. Correlation coefficients of different variables in breast cancer patients with thyroid dysfunction.

\begin{tabular}{|c|c|c|c|c|c|c|c|c|c|c|}
\hline Variables & PRL & FT4 & FT3 & TSH & TG-Ab & TPO-Ab & Estrogen & lodine & Selenium & TSHr-Ab \\
\hline PRL & 1 & -0.138 & 0.002 & 0.145 & -0.003 & -0.078 & 0.116 & 0.058 & 0.022 & 0.109 \\
\hline FT4 & & 1 & 0.19 & -0.136 & -0.009 & -0.172 & 0.045 & $-0.309^{*}$ & $0.356^{*}$ & -0.235 \\
\hline FT3 & & & 1 & 0.217 & -0.028 & -0.014 & -0.008 & -0.068 & 0.112 & 0.013 \\
\hline TSH & & & & 1 & -0.197 & 0.075 & -0.098 & 0.086 & 0.011 & -0.003 \\
\hline TG-Ab & & & & & 1 & 0.02 & 0.038 & 0.086 & -0.193 & 0.045 \\
\hline TPO-Ab & & & & & & 1 & -0.234 & 0.089 & -0.242 & -0.05 \\
\hline Estrogen & & & & & & & 1 & -0.276 & 0.006 & 0.132 \\
\hline lodine & & & & & & & & 1 & 0.109 & 0.065 \\
\hline Selenium & & & & & & & & & 1 & 0.012 \\
\hline TSHr-Ab & & & & & & & & & & 1 \\
\hline
\end{tabular}

*Significance $=0.05$. 


\section{Discussion}

Even though, a direct association has been revealed between thyroid disorders and breast cancer in recent studies, the precise mechanism of association between thyroid dysfunction and breast cancer is not yet to be explored. One likely reason was that $\mathrm{TH}$ in less quantity has a negative feedback effect on HPA which resulted in raised prolactin secretion in addition to TSH. Smyth et al. has reported no increase in prolactin levels in breast cancer but the findings were contrary to the results reported by Mittra et al. [24,25]. The present study also reported that there is an inverse correlation between Free T4 and Prolactin Levels (FT4 vs. PRL, $\mathrm{r}=-0.138$ ). The findings led the scientists to conceive an idea that reduced levels of $\mathrm{TH}$ act on breast tissue to stimulate prolactin causing dysplasia and then hyperplasia. Estrogen has been taken as a potential mitogen for normal breast tissue. On the other hand, thyroid hormones seem to induce lobular development causing differentiation of normal breast as in breast cancer, thyroid receptors have been illustrated [14]. T3 binds to estrogen receptor in addition to estrogen on breast neoplastic cells, thus enhances estrogenic effect and stimulate cell growth. This led to the hypothesis that raised T3 levels have an increased carcinogenic effect on breast tissue. Both thyroid and estrogen receptors are related to nuclear receptor family. The half sequence of nucleotide bases of thyroid hormone response element is similar to half sequence of ER response element. That's why TR has been likely to attach to ER response elements additionally to their respective response elements [14]. Decreased levels of T3 also present suppression of the hypothalamic-pituitary-thyroid axis and hyperprolactinemia.

The deficiency of dietary iodine and selenium intake has a significant role in induction of breast cancer. Kilbane et al., has suggested that iodine content of breast cancer tissue was greatly reduced as compared to normal thus predicting that in breast cancer there may be iodine uptake pathology [26]. Inhibitory effects may be exerted by iodinated compounds on adenylate cyclase and T. Sigma-iodolactone derivative of eicosapentaenoic acid is more effective in restraining growth than from other compounds. It has been reported that sigmaiodolactone might be produced from iodine by peroxidases only in the cells having NIS and peroxidases expression. However, there might be no effect of molecular iodine on thyroid neoplastic cells due to an absence of peroxidases. In breast cancer, deficient selenium levels induce down-regulation of $E R-\alpha$ gene expression and pro-angiogenic growth factors like VEGF resulting in cell proliferation. It has been revealed that seleno-methionine reduces inflammation and thyroid autoantibody concentrations at higher doses [27]. The current study also demonstrated inverse correlation between selenium and thyroid antibodies (Se vs. TPOAb, r=-0.242 and Se vs. TgAb, $\mathrm{r}=-0.193$ ). Selenium is also important for proper functioning of deiodinase and glutathione peroxidase, involved in thyroid hormone synthesis thus, its deficiency results in hypothyroidism leading to increased cancer mortality rates. The present study also depicted positive correlation between selenium and thyroid hormones (Se vs. FT3, $\mathrm{r}=0.112$ and $\mathrm{Se} v s$. $\mathrm{FT} 4, \mathrm{r}=0.356^{*}$ respectively).

Sodium Iodide Symporter (NIS) is a transport glycoprotein present in the plasma membrane. It expresses in thyroctes and also in extra thyroidal tissues like salivary glands, gastric mucosa and small intestines and of particular concern in current study, breast tissue. The Thyroid-Stimulating Hormone (TSH) regulates NIS expression in the thyrocyte. TSH activates the NIS promoter, NIS upstream enhancer and promotes the transport of the NIS to the plasma membrane. It is expressed in lactating breast tissue but not in non-lactating tissue where it trapped iodide which is secreted in milk. It has been reported by that $87 \%$ of breast neoplasms were positive for expression of NIS in comparison to $0 \%$ of the normal nonlactating breast tissues in breast cancer cells. It was assessed in mice that administration of oxytocin, prolactin and estrogen causes NIS expression in breast tissue but when each hormone introduced alone is insufficient to do so. Further reports hypothesized that repeated doses of oxytocin caused increased NIS expression in breast tissue. On the other hand, prolactin showed different results as in rats it increased NIS expression but in mice induction of prolactin alone or mixed with oxytocin did not elevate NIS expression. It was suggested that it was due to inhibitory effect of prolactin on estrogen synthesis which prevent NIS expression when combined with oxytocin also supported this hypothesis that when mice were treated with repeated high doses of estrogen, oxytocin and prolactin showed higher levels of NIS expression than those without estrogen. It was further proposed that NIS expression in breast cancer cells seemed to be independent of expression of TSHR, ER or PR. On contrary to it, association between ER and NIS induction has also been identified [28].

Serum anti-thyroperoxidase antibodies estimation is normally taken as a marker of thyroid autoimmunity. Turken et al. studied relationship of breast cancer with autoimmune thyroid disorders and high incidence of anti TPO-Ab in breast cancer was determined [29]. Different reports suggested a strong association [30]. Some results have also revealed that antithyroid peroxidase antibodies presence is related to enhancement in outcome in breast cancer [30]. Muller et al. explained that TPO mRNA and protein were not only restricted to thyrocytes but also displayed in other tissues like breast [31]. A latest analysis has proposed that adipocytes in breast cancer play a significant role in the development of $\mathrm{BC}$. Induction of TPO occurs in various fat reserves and breast is rich in fat thus expression of TPO can be explained. The process by which anti TPOAb may influence cancer development has not been completely explained. In thyroid gland, anti TPOAb presence seems to have a key role in antibody-mediated cell cytotoxicity. Thus an immune response may be generated by increased levels of anti TPOAb against 
breast neoplasm and/or thyroid. That's why, anti TPOAb presence showed markedly reduced occurrence of metastasis in patients affected with breast cancer [30]. The increased levels of anti-TPO anti-bodies correlated to breast cancer or common autoimmune reaction to malignancy still remain to be evaluated.

\section{Conclusion}

The present study shows an association in between thyroid disorders and breast cancer. Thyroid hormone profile may regulate breast cancer initiation as reduction in T3 levels resulted in higher levels of prolactin in breast cancer tissues leading to hyperplasia causing neoplasm development. Augmentation in thyroid auto-antibodies levels depicted decreased metastasis and enhancement of outcome in breast cancer. These variables may be used in prognosis as well as in controlling induction and progression of breast cancer.

\section{Acknowledgement}

The authors are highly thankful to Prof. Dr. M. H. Qazi, Center for Research in Molecular Medicine (CRiMM) to provide the innovative and financial support for the project

\section{Conflict of Interest}

Authors declare no conflict of interest.

\section{References}

1. Risk Factors Collaborators. Global, regional, and national comparative risk assessment of 79 behavioural, environmental and occupational, and metabolic risks or clusters of risks, 1990-2015: a systematic analysis for the Global Burden of Disease Study 2015. Lancet 2016; 388: 1659-1724.

2. Tomer Y, Huber A. The etiology of autoimmune thyroid disease: a story of genes and environment. J Autoimmun 2009; 231-239.

3. Silva JM, Dominguez G, Gonzales-Sanccho JM, Gracia JM, Silva J. Expression of thyroid hormone receptor/erbA genes is altered in human breast cancer. Oncogene 2002; 4307-4316.

4. Szychta P, Szychta W, Gesing A. TSH receptor antibodies have predictive value for breast cancer retrospective analysis. Thyroid Res 2013; 6: 8 .

5. Beatson GT. On the treatment of inoperable cases of carcinoma of the mamma: suggestions for a new method of treatment, with illustrative cases. Lancet 1986; 104-107.

6. Ditsch N, Susanne L, Von Koch F, Lenhard M, Vogeser M, Christine S. Thyroid function in breast cancer patients. Anticancer Res 2010; 1713-1718.

7. Angelousi AG, Anagnostou VK, Stamatakos MK, Georgios AG, Kontzoglou KC. Primary HT and risk for breast cancer: A systemic review and meta-analysis. Eur J Endocrinol 2012; 373-381.
8. Ali A, Manzoor RM, Bashir S, Hassan T. Impact of serum thyroid hormones and estrogen status on the risk of breast cancer in Kashmiri women. J Cell Sci Ther 2011; 1-3.

9. Takatani O, Okumoto T, Kosano H, Nishida M, Hiraide H, Tamakuma S. Relationship between the levels of serum thyroid hormones or estrogen status and the risk of breast cancer genesis in Japanese women. Cancer Res 1989; 3109-3112.

10. Shering SG, Zabar AP, Moriatry M. Thyroid disorders and breast cancer. Eur J Cancer Prev 1996; 504-506.

11. Anker GB, Lonning PE, Aakvaag. Thyroid function in post-menopausal breast cancer patients treated with tamoxifen. J Clin Lab Invest 1998; 103-107.

12. Enewold L, Zhu K, Ron E. Rising thyroid cancer incidence in the United States by demographic and tumor characteristics, 1980-2005. Cancer Epidemiol Biomarkers Prev 2009; 784-791.

13. Neville MC, McFadden TB, Forsyth I. Hormonal regulation of mammary differentiation and milk secretion. J Mammary Gland Biol Neoplasia 2002; 49-66.

14. Glass CK, Holoway JK. Regulation of gene expression by the thyroid hormone receptor. Biochimica et Biophysica Acta 1990; 157-176.

15. Utiger RD. Serum Triiodothyronine in Man. Ann Rev Med 1974; 289-302.

16. Thakur C, Saikia TC, Yadav RN. Total serum levels of triiodothyronine (T3) thyroxine (T4) and thyrotropine (TSH) in school going children of Dibrugarh district: an endemic goiter region of Assam. Indian J Physiol Pharmacol 1997; 167-170.

17. Soos M, Siddle K. Characterization of monoclonal antibodies directed against human thyroid stimulating hormone. J Immunol Methods 1982; 57-68.

18. Winter WE, Harris N, Schatz D. Immunological markers in the diagnosis and prediction of autoimmune Type 1a diabetes. Clin Diabet 2002; 183-191.

19. Kumkum A, Iaruine K, Shweta G, Ajulwar PN. Hyperprolacteveina and its concentration with hyperthyroidism in infertile women. Jobset Gyneiol India 2006; 68-71.

20. Farrell, Richmond. A rapid method for the estimation of serum protein-bound iodine. Clin Chim Acta 1961; 620-623.

21. Erickson GF. The ovary: Basic principles and concepts. Physiol Endocrinol Metab 1995; 3: 973-1015.

22. Combs GF, Clark LC. Selenium and cancer. In: Nutritional Oncology. Academic Press, San Diego, USA 1999; 215-222.

23. Hatanaka N, Nakaden H, Yamamoto Y. Selenium kinetics and changes in glutathione peroxidase activities in patients receiving long-term parenteral nutrition and effects of supplementation with selenite. Nutrition 2000; 22-26.

24. Smyth PPA, Smith DF, McDermott EWM, Murray MJ, Geraghty JG, O'Higgins NJ. A direct relationship between thyroid enlargement and breast carcinoma. J Clin Endocrinol Metab 1996; 937-941. 
25. Mittra I, Hayward JL. Hypothalamic-pituitary-prolactin axis in breast cancer. Lancet 1974; 889-891.

26. Kilbane MT, Ajjan RA, Weetman AP, Dwyer R, McDermott EW, O'Higgins NJ, Smyth PP. Tissue iodine content and serum mediated 125I uptake-blocking activity in breast cancer. J Clin Endocrinol Metab 2000; 1245-1250.

27. Turker O, Kumanlioglu K, Karapolat I, Dogan I. Selenium treatment in autoimmune thyroiditis: 9 month follow up with variable doses. J Endocrinol 2006; 151-156.

28. Chatterjee S, Malhotra R, Varghese F, Bukhari AB, Patel A, Budrukkar A, Parmar V, Gupta S, De A. Quantitative immune histo-chemical analysis reveals association between sodium iodide symporter and estrogen receptor expression in breast cancer. PLoS One 2013; 8.

29. Turken O, Narin Y, Demirbas S, Onde ME, Sayan O, Kandemir EG. Breast cancer in association with thyroid disorders. Breast Cancer Res 2003; 110-113.

30. Yasemin K, Demirag G, Kubilay E, Yucel I. Anti-thyroid peroxidase antibody positivity is associated with lower incidence of metastasis in breast cancer. Mol Clin Oncol 2015; 629-632.

31. Muller I, Giani C, Zhang L, Grennan-Jones FA, Fiore E, Belardi V. Does thyroid peroxidase provide an antigenic link between thyroid autoimmunity and breast cancer? Int J Cancer 2013; 1706-1714.

\section{*Correspondence to}

Arif Malik

Institute of Molecular Biology and Biotechnology (IMBB)

The University of Lahore

Lahore

Pakistan 